\title{
ATOS DE FALA NA ANÁLISE DO DISCURSO LITERÁRIO
}

Teresa Cristina Alves de Melo (Doutoranda na UFMG)

\section{Introdução}

O poder da palavra já é conhecido desde a Grécia Antiga, época em que a retórica vivenciava seu apogeu. O poder de persuasão da palavra foi estudado por inúmeros pensadores e usado para influenciar ou modificar a realidade em seus mais diversos aspectos. Desde então, discursos filosóficos, políticos, jurídicos e religiosos sempre obtiveram sucesso em conseguir adeptos, proferir sentenças, julgar, condenar ou perdoar integrantes do povo. Determinados proferimentos, inseridos num contexto próximo do ritual, determinam fatos sociais e deliberam, até mesmo, sobre a vida ou morte de pessoas. Sentenças proferidas em "rituais" como um julgamento ou casamento decidem o futuro das pessoas. Promessas, juramentos e declarações são tomados com extrema seriedade e seu poder de ação é normalmente reconhecido.

Outros discursos menos formais não deixam de apresentar o mesmo poder de ação e transformação em uma situação comunicacional. O poder da palavra é também reconhecido em situações de cunho muito popular como: "benzedura", "reza brava", "praga rogada" e o tradicional proferimento do "pacto com o diabo". Enunciados absolutamente cotidianos são, hoje, considerados de natureza performática. A linguagem está sempre buscando uma forma de agir sobre o outro, mesmo que se trate de uma situação comunicacional das mais informais. Tais conclusões foram tiradas, principalmente, da Teoria dos Atos de Fala, esboçada por Austin em meados da década de sessenta, cujas reflexões foram antecipadas por Charles Bally na década de vinte.

Neste artigo faremos uma breve introdução à Teoria dos Atos de Fala, em seguida aproximaremos as reflexões de Bally ao pensamento contemporâneo sobre tal assunto, revelando idéias antecipadoras do conceito. No intuito de nos inscrever 
na interface entre Lingüística e Literatura, buscaremos pelo menos um exemplo na obra de João Guimarães Rosa, Grande Sertão: Veredas, de um enunciado que demonstre de forma clara a performatividade da linguagem.

\section{A Teoria dos Atos de Fala}

A performatividade da linguagem é um assunto de grande circulação no âmbito da Lingüística, principalmente no que tange à Análise do Discurso. Esboçada, em princípio, por Austin, a Teoria dos Atos de Fala foi desenvolvida, em seguida, por Searle. Outros pensadores, como Habermas, Grice e Ducrot, contribuíram com importantes estudos sobre o assunto.

A teoria dos Atos de Fala considerava que determinadas sentenças ou proferimentos lingüísticos tinham natureza performativa, correspondendo à realização de ações. Enunciados clássicos como: "Eu os declaro marido e mulher" ou "Está encerrada a sessão" são sentenças que comprovam o poder da linguagem como um agente modificador da realidade. Assim sendo, alguns verbos foram considerados como sendo performáticos e responsáveis pelo caráter acional de certos enunciados: declarar, prometer, aprovar, avisar, apostar, pedir, etc.

Ainda nos primeiros estudos sobre a Teoria dos Atos de Fala, percebeu-se que em todo discurso existe performatividade. Sentenças, antes consideradas constatativas, foram aproximadas das performativas, no momento em que se notou que todo e qualquer enunciado pretende agir sobre o outro. Um comentário do tipo "Está escurecendo, parece que vai chover" poderia ser considerado como uma sentença constatativa. Mas, observando mais atentamente, tal comentário poderia provocar pelo menos uma olhadela pela janela por parte de um interlocutor, ou ainda, uma resposta, concordando ou não com o enunciado.

Mesmo que não seja um pedido, uma ordem, uma promessa ou um aviso, um discurso sempre busca agir sobre o interlocutor e espera uma reação deste. Contar uma piada, uma história, uma experiência individual são ações comunicativas que pretendem causar algum efeito na relação dos interlocutores. 
Há, nessas ações, sempre, uma intenção de fazer rir, emocionar, chocar, surpreender, agradar ou desagradar o outro. Tais exemplos vêm comprovar que a linguagem é possuidora de uma força ilocutória com grande poder de transformação nas situações comunicacionais.

\section{Charles Bally}

Embora Austin tenha sido o primeiro a teorizar sobre os atos de fala, o lingüista Charles Bally antecipa, em seus escritos, algumas idéias sobre o poder de ação da linguagem. Mais conhecido como um dos discípulos de Saussure, cujas anotações foram utilizadas na composição da obra póstuma de seu mestre Cours de Linguistique général, Bally possui sua própria obra sobre lingüística. Seu livro Le langage et la vie, publicado pela primeira vez em 1925, é um conjunto de diversas publicações relativas a problemas fundamentais de lingüística geral, reunidas em um volume. Esta obra nos interessa em particular pelo fato de conter idéias passíveis de serem aproximadas da atual Teoria dos Atos de Fala. O autor deixa claro, já no "Sommaire", o reconhecimento da linguagem enquanto expressão de sentimentos e instrumento de ação.

Para Bally a língua é a expressão da vida e não se trata de uma criação lógica. Elementos da subjetividade e da afetividade estão presentes em qualquer enunciado, e são estes elementos que fazem com que a linguagem seja, não só compreendida, como também sentida e vivida. Os produtos da linguagem não são inteiramente intelectuais, pois a subjetividade do pensamento se mostra presente:

Lorsqu'il nous arrive de dire qu'il fait chaud, qu'il fait froid ou qu'il pleut, il ne s'agit presque jamais d'une simple constatation mais d'une impression affective, ou bien d'un jugement pratique, susceptible de déterminer une action; (Bally, 1965: 17).

A linguagem não é apenas um instrumento de constatação ou descrição de fatos, ela tem um caráter social, ativo, que faz da palavra uma ação:

Le langage devient alors une arme de combat: il s'agit d'imposer sa pensée aux autres; on persuade, on prie, on ordonne, on défend; ou bien, parfois, la parole se replie et cède: on ménage l'interlocuteur, 
on esquive son attaque, on cherche à capter sa faveur, ou bien on lui témoigne son respect, son admiration. (Bally, 1965: 18).

Embora Bally não utilize a expressão "atos de fala", o fato de considerar a linguagem como a união de elementos intelectuais, subjetivos e afetivos, e ainda, como um instrumento de expressão e ação na vida real, o aproxima de toda a teoria desenvolvida posteriormente por outros pensadores.

Mais do que outros lingüistas, Bally tomou a linguagem na vida real, não perdeu tempo em isolá-la ou tratá-la como algo independente de todo um contexto social e afetivo, mostrando grande sensibilidade em reconhecê-la como parte integrante e indissociável da vida. Tratou os enunciados em seu contexto situacional, levando em consideração elementos presentes em cada ato comunicativo. Contribuiu com diversos pensamentos cujo potencial de desenvolvimento foi largamente aproveitado pelos analistas do discurso da posteridade.

\section{Um Ato de Fala de Riobaldo}

A Análise do Discurso tem estudado os mais diversos tipos de textos: o publicitário, o político, o pedagógico, o jurídico, o jornalístico, etc. Observamos, entretanto, que os estudos lingüísticos sobre o texto literário são menos freqüentes, o que nos faz pensar que a Lingüística apresenta certo pudor com relação à Literatura. Muitos teóricos insistem em dissociar completamente estudos lingüísticos e literários, em considerar a Lingüística uma ciência, a Literatura uma arte e ver uma impossibilidade em associá-las.

Nosso artigo pretende abordar o texto literário dentro de perspectivas discursivas e lançar um novo olhar sobre a narrativa rosiana sob a ótica dos estudos lingüísticos. Tomaremos um único enunciado de Grande sertão: Veredas para exemplificar a performatividade da linguagem.

A narrativa rosiana conta a história de amor de Diadorim e Riobaldo e tem como cenário a guerra entre jagunços do sertão mineiro. Diadorim era filho de Joca Ramiro, o chefe dos jagunços assassinado por traidores. Riobaldo, mesmo fazendo 
parte do bando, não tinha conhecimento deste fato. Após a morte de Joca Ramiro, o bando fez uma parada em Aroeirinha, onde Riobaldo conheceu a filha da benzedeira Ana Duduza, Nhorinhá, com quem teve um caso amoroso. Diadorim, cuja identidade feminina era também desconhecida por Riobaldo, ao desconfiar do afeto de Riobaldo por Nhorinhá, sentiu ciúmes e para se vingar disse ter razões para matar Ana Duduza. Durante a discussão sobre a morte de Ana Duduza, Diadorim confessa a Riobaldo que era filho de Joca Ramiro, ao que, embora surpreso, Riobaldo rebate: "Pois, para mim, para quem ouvir, no fato essa Ana Duduza fica sendo minha mãe”. Enunciado de grande impacto que, mesmo não sendo real, se torna uma grande verdade. Ao ser pronunciado, age sobre Diadorim que dá por encerrada a discussão e desiste de matar Ana Duduza.

No implícito deste enunciado está todo seu poder de persuasão. Riobaldo expressa toda sua disposição em evitar a morte de Ana Duduza. Evoca a palavra "mãe" com todo seu poder tradicional de ente que deve ser respeitado e protegido. Coloca-se em posição incontestável de protetor e Ana Duduza na condição de intocável. O faz com tanta determinação que coloca um fim no impasse. Trata-se de uma atitude premeditada de convencer o outro, impor sua vontade por meio das palavras, mesmo que essas possuam uma verdade somente enquanto palavras:

Quiconque pense avec intensité ou veut imposer se pensée, ne peut y parvenir qu'en faussant la realité et la verité. (Bally, 1965: 18,19).

O efeito do enunciado é tão eficiente quanto seria se Ana Duduza fosse, realmente, mãe de Riobaldo. Esta eficiência só é possível porque os interlocutores partilham de saberes sociais que tornam a figura da mãe como sendo "sagrada". Um enunciado, para ter poder de ação e de transformação da realidade, deve ser pertinente à situação comunicacional. O enunciador deve ter conhecimento do que poderia causar algum efeito e provocar a reação desejada em seu interlocutor. É pelo uso da linguagem que o locutor procura impor sua vontade.

La langue apparaîtra comme une arme que chaque interlocuteur manie en vue de l'action, pour imposer sa pensée personelle.( Bally, 1965: 21). 
O exemplo por nós escolhido é um enunciado aparentemente simples. Não se trata de um discurso de grandes proporções e a situação se apresenta de maneira bastante informal. Em contrapartida, seu pronunciamento foi extremamente performático e persuasivo, sendo capaz de modificar todo um contexto situacional em favor da vontade do enunciador. Todo e qualquer enunciado apresenta maior ou menor grau de performatividade e é isso que faz com que a linguagem seja capaz, por si própria, de modificar a realidade dos interlocutores nas mais diversas situações.

\section{Referências Bibliográficas}

BALLY, C. Le langage et la vie. Genebra: Librairie Droz, 1965.

CHABROL, C.; BROMBERG, M. "Por uma classificação dos atos de fala". In: MARI, H.; MACHADO, I. L. e MELLO, R. (org.). Análise do discurso: fundamentos epráticas. Belo Horizonte: NAD/FALE/UFMG, 2001.

GARCÍA-VIEIRA, U. "Psicológica e sociológica dos atos de fala: Searle e Habermas". In: MACHADO, I. L., MARI, H. e MELLO, R. (org.) Ensaios em Análise do Discurso. Belo Horizonte: NAD/FALE/UFMG, 2002.

MARI, H. “Atos de fala: notas sobre origens, fundamentos e estrutura.” In: MARI, H.; MACHADO, I. L. e MELLO, R. (org.). Análise do discurso: fundamentos e práticas. Belo Horizonte: NAD/FALE/UFMG, 2001.

PAZ, F. de S. "Ato assertativo, verdade e crença na Teoria dos Atos de Fala". In: MACHADO, I. L., MARI, H. e MELLO, R. (org.) Ensaios em Análise do Discurso. Belo Horizonte: NAD/FALE/UFMG, 2002.

ROSA, J. G. Grande sertão: Veredas. Rio de Janeiro: Editora Nova Fronteira, 2001. 